


\section{Cultura de Paz na Escolinha de Artes: diálogos necessários}

Juliana Rossi Gonçalves Maria Lúcia Costa Rodrigues

Recebido em: 15/05/2019

Aprovado em: 04/06/2019

DOI: 10.5965/2358092521212019045 


\section{RESUMO}

A Escolinha de Artes de Joinville, assim como as que restaram no Brasil, resiste ao tempo e às mudanças políticas e metodológicas, renovando-se a cada ano com a dedicação de seu corpo docente. O seu contexto de criação relaciona-se ao Movimento Escolinhas de Arte (MEA) do Brasil. Desde a década de 1990, a cada ano a Escolinha de Artes de Joinville trabalha um tema com os alunos, que culmina em uma exposição didática e apresentações de teatro. Este texto apresenta e analisa o projeto realizado em 2016 cujo tema foi Cultura de Paz. Sua culminância se deu com a exposição realizada na Galeria Municipal de Artes Victor Kursancew e os frutos gerados para a comunidade. Com base no relato do projeto, o presente texto faz um breve panorama histórico dos 49 anos de existência da Escolinha, discutindo seu papel como instituição de formação artística das crianças, dentro de um espaço não formal de ensino da arte.

Palavras-chave: escolinha de arte; cultura de paz; ensino da arte.

\section{A ESCOLINHA DE ARTES DE JOINVILLE/SC: CRIAÇÃO, METODOLOGIA E CONTEXTUALIZAÇÃO HISTÓRICA}

O contexto efervescente nas artes da cidade de Joinville (SC), na década de 1970, foi propício para a criação da Escolinha de Artes Infantis (EAI). Nessa década e na seguinte o poder público disponibilizou mais recursos na criação de espaços públicos de salvaguarda de bens culturais e de educação para a arte, marcando as décadas de 1970 e 1980 como as mais prósperas para a arte e cultura de Joinville. Nessas duas décadas foi criada grande parte dos museus e instituições culturais da cidade. Os museus continuam ativos até 
hoje, como o Museu de Arte de Joinville (MAJ), o Museu Casa Fritz Alt e a Galeria Municipal de Artes Victor Kursancew (GMAVK). Além de museus, diversos movimentos culturais e artísticos foram criados e permanecem até hoje, como por exemplo: a Coletiva dos Artistas e a Associação dos Artistas Plásticos de Joinville (AAPLAJ).

A Escolinha ${ }^{1}$ de Joinville (SC) nasceu em 1970, dois anos após a criação da Escola de Artes Fritz Alt (EAFA), uma escola pública de ensino não formal em arte. A criação da EAFA se opôs ao contexto escolar tecnocrático da época na cidade, voltado ao preparo de mão de obra da indústria (MOKROSS, 1992), talvez resquícios da educação do Estado Novo.

A idealizadora da Escolinha foi a produtora cultural Albertina Ferraz Tuma. A ideia surgiu quando Albertina fez um curso de Arte-Educação no Museu e Escola de Arte do Paraná, em Curitiba (PR). Na época, Albertina também desenvolvia seu trabalho como artista plástica, sendo uma das artistas que participou da 1. ${ }^{a}$ Coletiva de Artistas da cidade, em 1971. Depois de criar a Escolinha, foi admitida como professora e mais tarde assumiu como diretora da EAFA e diretora geral da Casa da Cultura Fausto Rocha Júnior².

Em seu início, a Escolinha ocupou uma pequena sala no prédio da antiga Prefeitura de Joinville, que ficava localizada na Rua Padre Carlos (STEFFEN, 1999). A faixa etária dos alunos era dos 4 aos 12 anos. Depois de seis anos de criação, a Escolinha contava com mais de 106 alunos (VI COLETIVA, 1976).

Em 1971 a Escolinha passou a ocupar uma sala no Departamento de Educação e Cultura, que funcionava no antigo prédio dos Correios e Telégrafos, na Praça Nereu Ramos. Atualmente nesse espaço funciona o Instituto de Previdência Social dos Ser-

1 Quando citamos "Escolinha", estamos nos referindo à Escolinha de Artes Infantis da Casa da Cultura Fausto Rocha Júnior de Joinville (SC).

2 A Casa da Cultura Fausto Rocha Júnior, um espaço público mantido pela Prefeitura de Joinville por meio da Secretaria de Cultura e Turismo (SECULT), teve sua inauguração oficial em janeiro de 1973. Nesse espaço funciona a Escola de Artes Fritz Alt (EAFA), a Escola de Música Villa Lobos (EMVL), a Escola Municipal de Ballet (EMB), a Galeria Municipal de Artes Victor Kursancew (GMAVK) e a Biblioteca Edith Wetzel. A Casa da Cultura localiza-se na Rua Dona Francisca, 800, no bairro Saguaçu, em Joinville (SC). 
vidores Públicos do Município de Joinville (IPREVILLE).

No primeiro ano da Escolinha, além de exposições em um restaurante e livrarias, realizou-se o $1^{\circ}$ Festival (Coletiva) de Artes Infantis (figura 1), no salão da Secretaria de Educação e Cultura do município. A exposição obteve reconhecimento e sucesso na comunidade joinvilense, demonstrando a seriedade de um trabalho voltado à expressão e educação para crianças por meio da arte (STEFFEN, 1999).

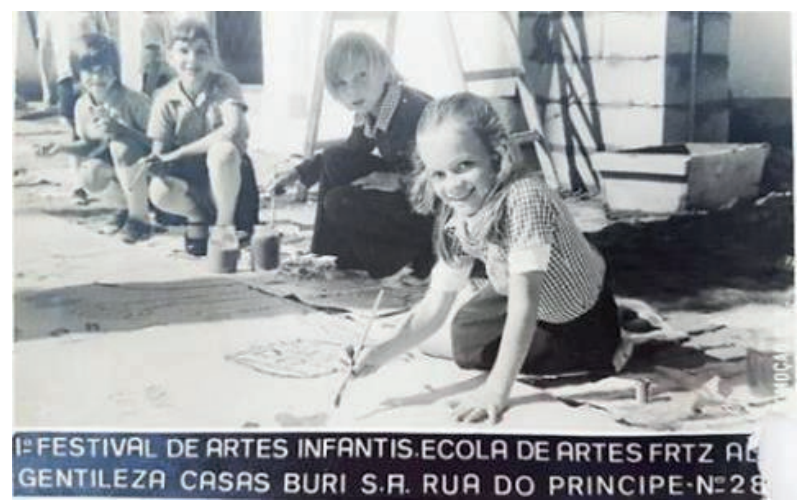

Figura 1: Cartaz do 1. ${ }^{\circ}$ Festival de Artes Infantis da Escolinha de Joinville, em 1971 Fonte: Cópia de cartaz impresso. Autoria desconhecida

Em 1972, com a construção da Casa da Cultura Fausto Rocha Júnior pelo poder público, a Escolinha recebeu sede própria. A Casa da Cultura ${ }^{3}$ não só fortaleceu a cidade artisticamente, como também impulsionou o ensino da arte, fazendo com que a Escolinha passasse a ter uma sala própria, ampla e adequada para suas ações educativas.

No mesmo ano a Escolinha promoveu um curso de Arte na Educação voltado aos professores da Rede Municipal de Ensino. Além desse, vários cursos de formação em arte-educação foram ofertados pela Escolinha aos professores de Joinville e região ao

3 Neste artigo, "Casa da Cultura" refere-se à Casa da Cultura Fausto Rocha Júnior. 
longo dos anos. Em 1982, 51 professores participaram do 2. ${ }^{\circ}$ Curso de Treinamento para professores em arte-educação. Tais cursos marcam o pioneirismo na formação de arte-educadores na cidade, em um momento que não havia cursos de ensino superior em artes no Brasil, seguindo o exemplo da Escolinha de Arte do Brasil (EAB) ${ }^{4}$.

Inicialmente pautada na livre-expressão, a Escolinha de Joinville circundou o Movimento Escolinhas de Arte (MEA) do Brasil, que marcou o modernismo no ensino da arte. Segundo lavelberg (2015, p. 33), "os arte-educadores modernos enalteceram a produção artística espontânea da criança para libertar seus atos criativos e, assim, a arte infantil ganhou existência e validação na educação". Os alunos eram levados para fora da escola para poderem se expressar em tapumes e paredes pela cidade. Em 1993 foram incorporadas à Escolinha aulas de teatro, contemplando assim uma abordagem mais ampla e social na educação pela arte.

Na década de 1990 ocorreu a introdução de novas concepções teóricas na Escolinha de Joinville, mudando sua estrutura filosófica e metodológica. Projetos com temas norteadores pautados pela História da Arte e a Abordagem Triangular $^{5}$ de Ana Mae Barbosa foram adotados na década de 1990 (STEFFEN, 1999), marcando a entrada do ensino da arte pós-moderno na instituição. Desde então, a elaboração de atividades é pautada em projetos anuais que abordam temas diversos e que são trabalhados ao longo do ano no ateliê de artes visuais e na sala de teatro, culminando na exposição didática anual da Escolinha e na apresentação de peças de teatro no fim do segundo semestre.

4 A EAB foi a primeira escolinha de arte criada no Brasil, o que ocorreu em 1948 por Augusto Rodrigues, no Rio de Janeiro (RJ), marcando o início do Movimento Escolinhas de Arte (MEA). Rodrigues foi influenciado pelas ideias do inglês Herbert Read, por meio do livro "Educação através da arte" (1943), e por Viktor Lowenfeld, com sua obra "Desenvolvimento da capacidade criadora" (1947). O MEA foi influenciado por vários artistas, educadores e professores que se destacaram em sua implantação, como: Noemia Varela, Margaret Spencer e Lucia Valentim (BARBOSA, 2008). Além das aulas voltadas ao público infantil, a EAB oferecia cursos de formação em arte-educação para professores.

5 A Abordagem Triangular possui três eixos norteadores para o ensino da arte: fazer artístico, leitura de imagem, contextualização. Idealizada por Ana Mae Barbosa, a abordagem possui influência do Critical Studies inglês, das Escuelas Al Aire Libre mexicanas e do Discipline-Based Arts Education (DBAE) norte-americano (RIZZI, 2008). 
Atualmente a Escolinha possui 133 alunos, cuja faixa etária é dos 6 aos 12 anos. O corpo docente divide-se entre arte-educadores da área de Artes Visuais e arte-educadores da área de Teatro, todos funcionários públicos municipais concursados e com formação na área. As turmas são divididas por faixa etária, e as aulas acontecem uma vez por semana, por turma, com duração total de $3 \mathrm{~h} 20 \mathrm{~min}$. Ao todo são oito turmas compostas de no máximo 22 alunos, que durante as aulas se separam em dois grupos, alternando entre aulas no ateliê e no teatro. Ressalta-se que todos passam pelas duas linguagens no período.

Importante esclarecer que os temas também têm sofrido mudanças - o corpo docente vem levando em consideração as vozes das crianças, o que aparece em suas falas e fazeres artísticos, que revelam a influência de suas vivências cotidianas fora da sala de aula. Os títulos dos temas e a expografia dos trabalhos são mediados pelos professores, discutidos e então escolhidos pelas crianças (figura 2) quase no final do projeto, no momento em que a equipe docente considera que os educandos estejam familiarizados e envolvidos com as atividades e temática proposta.

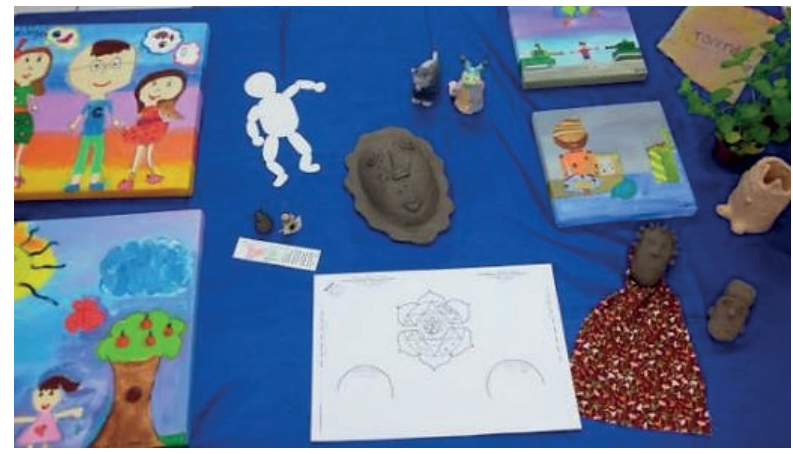

Figura 2: Mesa expositiva com exemplos de trabalhos das diferentes turmas e planta baixa (centro da foto, embaixo) do projeto expositivo da 46. ${ }^{\text {a }}$ Exposição da Escolinha (2016) para compartilhamento com todas as turmas

Fonte: foto de Maria Lúcia Costa Rodrigues. 
Com o passar dos anos os projetos foram ganhando força e se aproximando mais do contexto sociocultural das próprias crianças. Como exemplo, os temas que foram trabalhados na Escolinha nos últimos anos: "A cultura tem o poder e me ajuda a viver" (2018), "La América del Sol" (2017), "O que é paz para mim?" (2016), “O circo que mora em mim" (2015) e "O mundo que me toca" (2014). Neste texto enfocamos o projeto Cultura de Paz, de 2016, e sua exposição intitulada "O que é paz para mim?".

\section{POR QUE PENSAR CULTURA DE PAZ NA ARTE-EDUCAÇÃO?}

A promoção à vida, a tolerância, o cuidado com o meio ambiente são temas que encontram eco nos mais diversos discursos. Porém as práticas diárias mostram que esses temas ainda estão muito distantes da realidade da maioria das crianças. Por que isso acontece? Embora os temas sejam abordados na escola e às vezes na família, as crianças recebem um arsenal de informações diárias pelos canais de TV, internet e jogos digitais que banalizam o consumo, a violência e a intolerância.

Há mais de um século esforços vêm sendo feitos pela paz e pela não violência entre os povos. Exemplos são a Conferência de Haia de 1899, a Liga das Nações de 1919, a Organização das Nações Unidas (ONU) e sua agência especializada para a educação, a Organização das Nações Unidas para a Educação, a Ciência e a Cultura (UNESCO), e a Declaração Universal dos Direitos Humanos de 1948.

Apesar de tantas ações positivas em relação à paz entre as nações, o mundo tem passado nos últimos anos por mudanças em relação às suas fronteiras culturais e geográficas. A ascensão de grupos radicais pelo mundo, as mazelas sociais e as guerras provocaram um aumento expressivo de imigrações para os países desenvolvidos ou neutros em suas relações internacionais. O diferente causa insegurança e intolerância entre culturas distintas, o que frequentemente pro- 
voca preconceito e discriminação antes mesmo de conhecer o outro e as razões que o levaram a abandonar seu país de origem.

Além dessas grandes imigrações pelo mundo, o incentivo ao consumo desenfreado por meio de produtos industrializados e bens de consumo são algumas das causas de um desequilíbrio socioeconômico e ambiental no Brasil e em vários países. Contudo, mesmo diante desse panorama, surgem todos os dias nos bairros das cidades agentes transformadores que vêm quebrar esse ciclo, promovendo desenvolvimento humano, solidariedade, empatia, tolerância e gentileza por intermédio de projetos humanitários e culturais. Em Joinville existem alguns projetos, como por exemplo o OMUNGA Educação, que leva livros para a África e escolas do Sertão; Fundação Pe. Fachini Pró-Solidariedade e Vida, que promove a erradicação da fome infantil na cidade; Missão Criança, que oferece reforço escolar, esportes e artes no contraturno escolar para crianças de um bairro periférico da cidade.

A Cultura de Paz existe porque o antagônico existe: a guerra, a fome e a violência. Portanto, falar de paz implica falar das guerras, injustiças e dos problemas causados pela ação humana no planeta. A manutenção da paz é uma construção diária; não se constrói uma educação pela paz escondendo, velando ou minimizando os problemas ou ainda buscando tão somente a paz individual e esquecendo o ser social.

Paulo Freire propôs que a manutenção da paz seria consequência de uma educação crítica e conscientizadora: "Não creio em nenhum esforço chamado de educação para a Paz que, em lugar de desvelar o mundo das injustiças, o torna opaco e tenta miopizar as suas vítimas" (FREIRE apud FREIRE, 2006, p. 388).

Não é possível num mundo globalizado pensar em uma educação para a paz cuidando apenas de si próprio, pois vivemos em comunidade. As ações de um sujeito que pertence à mesma comunidade de outro sujeito interferem diretamente no seu modo de vida. Todavia o indivíduo social e empático necessita de um fortalecimento emocional para 
o combate às injustiças na manutenção da paz. A percepção das influências das emoções no corpo físico pode ser estudada pela Hermenêutica, um campo da filosofia que interpreta subjetivamente o indivíduo por meio da relação dele com o mundo (CAPRARA, 2003). Portanto, a Cultura de Paz também está associada à saúde física e mental, tanto quanto à educação. Assim, o indivíduo e ser social devem estar em equilíbrio. Então, como buscar uma Cultura de Paz por meio da educação que pense nesse equilíbrio entre o indivíduo e comunidade?

Uma educação promovedora da paz que pense de forma equilibrada o ser social/empático e o ser emocional/indivíduo encontra eco nas Ciências Humanas, entre elas a arte. É cabível que na arte o equilíbrio e o fortalecimento entre o indivíduo e a sociedade encontrem resultados eficazes, especialmente quando é possível vivenciar mais de uma linguagem artística, priorizando em suas diferenças a formação emocional, crítica e social da criança, além de suas habilidades técnicas, expressivas e criativas.

A arte como antena do mundo busca meios de fomentar temas que são sensíveis ao contexto histórico vivido. Nesse caso, onde se discute a promoção da cultura de paz, os pequenos nichos transformadores e promotores do bem-estar social podem estar presentes em um professor, num agente comunitário, num artista ou numa associação de bairro. É necessário que esses agentes transformadores sejam cada vez mais incentivados e revelados à comunidade e sobretudo às crianças, que carecem de exemplos de esperança e humanidade. Foi pensando nesses pequenos nichos transformadores que a Escolinha de Artes Infantis, mediante o projeto de 2016, desenvolveu ações e atividades para a promoção da Cultura de Paz por meio da arte.

Participaram do projeto 130 crianças e uma equipe de sete professores; quatro do ateliê de Artes Visuais (Andreia Schmitz Vicente, Daniele Rieper, Juliana Georg Bender e Maria Lúcia Costa Rodrigues) e os outros três do Teatro (Amarildo de Almeida, Juciara Nascimento e Robson Benta). A equipe 
contou ainda com o apoio das coordenações da Casa da Cultura, com os parceiros da ONG Missão Criança, Associação de Haitianos de Joinville e ONG Lixo Zero.

\section{CULTURA DE PAZ NA ESCOLINHA DE ARTES DE JOINVILLE: SENSIBILIZAÇÃO E PROCESSOS ARTÍSTICOS}

Abordar a Cultura de Paz por meio do ensino da arte na infância possibilita a sensibilização e o fortalecimento do pensar crítico social por intermédio da pesquisa, experimentação, apreciação e contextualização. Partindo da premissa de que a Cultura de Paz é um conceito a ser apreendido desde a infância para que seja naturalizada, a arte tem papel fundamental na promoção e manutenção da paz.

Ao pensar no projeto e nas atividades a serem desenvolvidas, alguns conflitos surgiram ainda durante a sua elaboração. O núcleo de professores deparou com realidades conflitantes dentro da própria equipe, formada por pessoas de orientações religiosas diversas e pensamentos divergentes com relação à abordagem do tema, visto que este muitas vezes é associado à espiritualidade. Tal experiência mostrou que um distanciamento do objeto de estudo, mais que uma experimentação prática, pelo menos no que constituiu a elaboração do projeto, foi necessário. Essa ação veio provar que a promoção da paz, além de ações, requer a argumentação, a escuta e a aceitação do diferente.

Para fundamentar os caminhos percorridos e minimizar a possibilidade de novas divergências entre todos os envolvidos, durante o processo de elaboração do projeto foram apresentadas fontes como: literaturas, a Constituição de 1988, a Declaração Universal dos Direitos Humanos e outros documentos históricos para a promoção da paz. Essas fontes e a convicção da equipe em trabaIhar na laicidade como mantenedora de uma neutralidade garantiram um bom andamento do projeto. Ou seja, trabalhar o tema em questão não só procurou trazer à luz os conceitos da Cultura de 
Paz para as crianças, como também contribuiu para o crescimento da própria equipe que o conduziu.

Tendo em vista todas essas percepções iniciais, a Escolinha de Artes, por meio de sua equipe, desenvolveu o tema com base em três eixos norteadores, procurando contemplar ações que promovessem a manutenção da paz. Os três eixos escolhidos para o desenvolvimento do projeto foram: 1) Meio ambiente - poluição, recursos findáveis, animais em extinção; 2) Multiculturalismo - migrações pelo mundo causadas pela guerra, fome e desigualdades sociais; 3) Combate às injustiças sociais - estabelecer contato com projetos sociais periféricos que mudam positivamente a realidade social, promovendo assim a Cultura de Paz.

As ações de sensibilização e práticas em sala de aula para o tema "Meio ambiente" foram as seguintes: passeios ao entorno da Casa da Cultura, especialmente em seu bosque e Rio Cachoeira (figura 3), com realização de intervenções artísticas (figura 4); contações de histórias e disponibilização de livros de literatura infantil sobre a temática ambiental e sobre animais em extinção para leitura dos alunos. Todas essas ações resultaram em campanhas de salvaguarda da natureza, produção de cápsulas de argila com sementes para disseminação do plantio de plantas, produção de cerâmicas e pinturas retratando animais em extinção e os ambientes em que vivem. Além disso, realizaram-se oficinas de manejo de rejeitos e orgânicos, campanha da Escolinha que envolveu toda a comunidade da Casa da Cultura para implantação efetiva do Programa Lixo Zero em suas dependências por meio de uma parceria com a ONG Lixo Zero de Joinville ${ }^{6}$.

6 A ONG visa promover o Conceito Lixo Zero na cidade de Joinville, mediante eventos, palestras, oficinas e campanhas, valorizando o meio ambiente e a sociedade. O objetivo do Programa Lixo Zero é "criar alternativas dinâmicas de conscientização e gestão sobre os resíduos que geramos, a fim de tornar Joinville uma cidade mais sustentável e consciente" (JOINVILLE LIXO ZERO, 2016). 


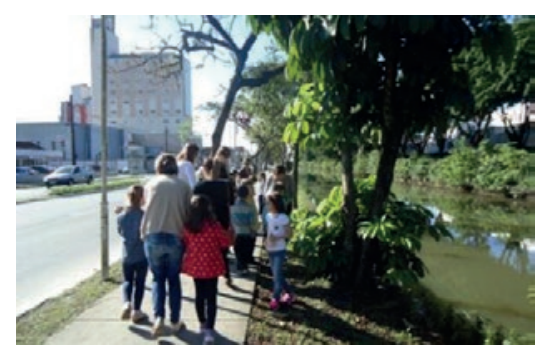

Figura 3: Passeio com os alunos à beira do Rio Cachoeira, principal rio que corta boa parte da área urbana de Joinville

Fonte: Foto de Juciara Nascimento

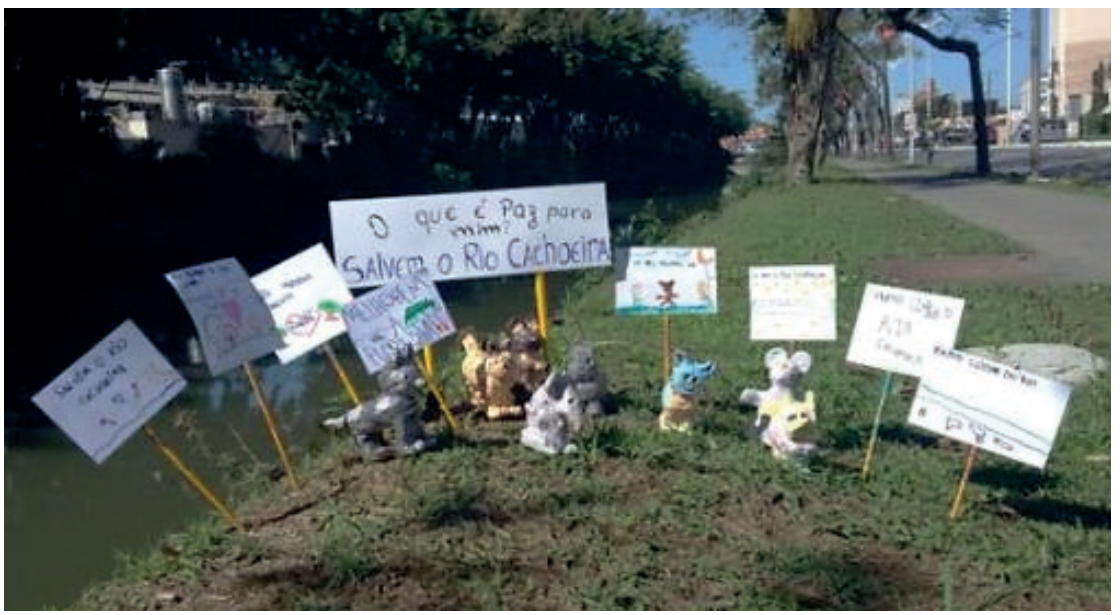

Figura 4: Intervenção urbana às margens do Rio Cachoeira com animais em cerâmica e cartazes produzidos pelos alunos de 6 anos

Fonte: Foto de Maria Lúcia Costa Rodrigues

No segundo eixo, "Multiculturalismo", abordaram-se a diversidade cultural e as imigrações de povos (figura 5). Trata-se de um tema muito significativo e necessário diante da realidade micro e macro das sociedades atuais. Vemos diariamente em jornais, revistas e portais de notícias os movimentos imigratórios de povos de diversos países em crise pelo 
mundo. Com base nesse tema trazido a uma esfera local, a Escolinha oportunizou o aprendizado do respeito às diferenças culturais - sentimento que as crianças não só levaram para casa, como também para a escola e vida. De acordo com Barbosa (2011, p. 19), "o compromisso com a diversidade cultural é enfatizado pela Arte-Educação Pós-moderna. Não mais somente os códigos europeus e norte-americanos brancos, porém mais atenção à diversidade de códigos em função de [...] etnias, gênero, classe social etc.".

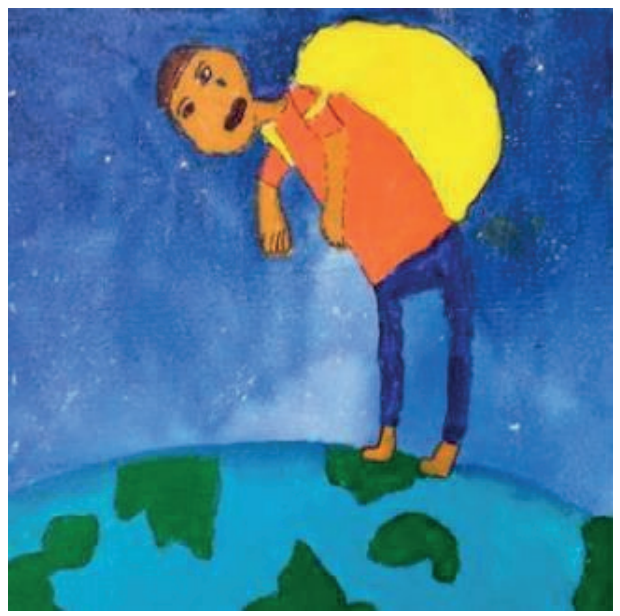

Figura 5: Pintura da aluna Mara, de 11 anos, representando a imigração

Fonte: Foto de Maria Lúcia Costa Rodrigues

Como ações concretas de sensibilização para o tema imigração e diversidade cultural, foram contatados o Presidente da Associação dos Imigrantes Haitianos de Joinville, Sr. Whistler, e uma jovem haitiana que vive em Joinville, Shama Edme, os quais participaram de uma roda de conversa com os alunos. Com essas conversas, as crianças puderam compreender um pouco da cultura e dos motivos que causaram a imigração dos haitianos. Por meio de tal contextualização os alunos desenvolveram trabalhos artísticos e expressivos 
materializados em pinturas e máscaras em cerâmica, que refletiram sobre o respeito às diferenças culturais.

Por fim, para o terceiro eixo, cujo tema é "Combate às injustiças sociais" como promoção da Cultura de Paz, escolheram-se dois projetos que promovem o bem-estar de crianças em risco social. O primeiro foi a Fundação Aquarela de Bogotá, representada por Elizabeth Mendonça Fontes (Beth Fontes), musicista e escritora mineira, atualmente residente em Joinville. Beth Fontes fez parte da Fundação Aquarela durante seis anos. A Fundação promove ações em cinco instituições de Bogotá que atendem crianças com câncer e crianças em risco social por meio de projetos de integração, música, contação de histórias e campanhas de arrecadação de mantimentos e medicamento para as instituições. Elizabeth ensaiou (figura 6) com as crianças da Escolinha a música O amor é a cura, de Cecília Cavalieri França, que foi apresentada na abertura da Exposição no dia 3 de novembro de 2016.

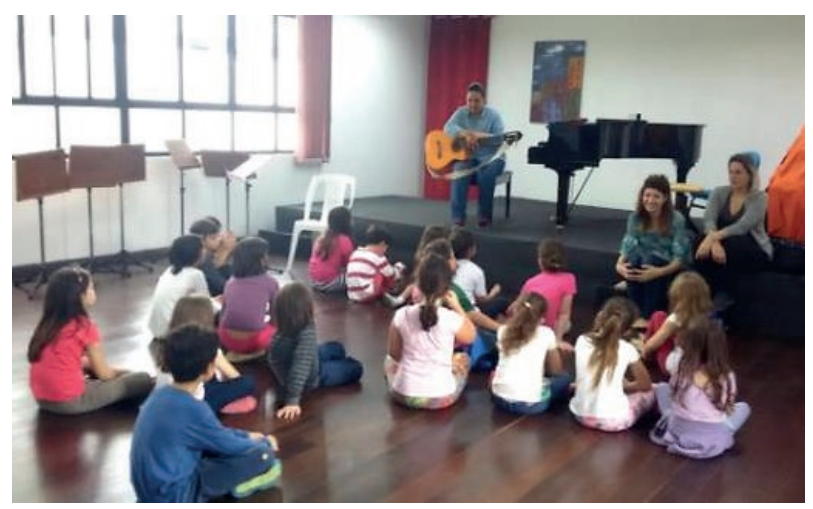

Figura 6: Ensaio com os alunos da Escolinha no Auditório da Casa da Cultura para apresentação musical na Abertura da 46a Exposição7.

Fonte: Foto de Maria Lúcia Costa Rodrigues

7 Na foto estão presentes Elizabeth Fontes (musicista e escritora) com o violão e, à direita, estão as professoras da Escolinha Andreia Schmitz Vicente e Daniele Rieper. 
O outro projeto escolhido foi um local: ONG Missão Criança. As crianças da Escolinha fizeram uma integração com essa ONG do bairro Jardim Paraíso, uma localidade da periferia de Joinville. As crianças das duas instituições trocaram cartas e construíram autorretratos em bonecos articulados de papel (figura 7). Durante o período expositivo do projeto as crianças da ONG fizeram uma visita à Escolinha e tiveram a oportunidade de ver seus trabalhos expostos na Galeria Municipal de Artes Victor Kursancew.

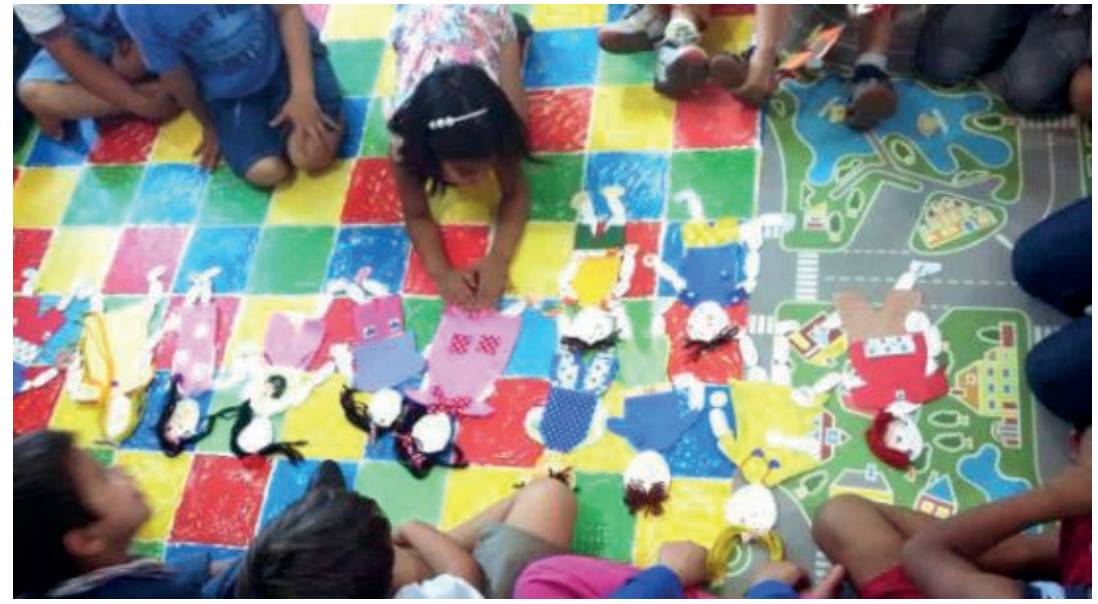

Figura 7: Construção de autorretratos com bonecos articulados na ONG Missão Criança, com ação educativa dos professores da Escolinha

Fonte: Foto de Maria Lúcia Costa Rodrigues

Para os três eixos as crianças estudaram pessoas, escritores e artistas que, por meio de suas ações e arte, promoveram a Cultura de Paz, como o artista Vik Muniz, o escritor Cláudio Martins e o Profeta Gentileza. Os eixos "Meio ambiente" e "Multiculturalismo" transitaram entre diferentes faixas etárias na Escolinha.

Parte dos trabalhos foi realizada por todos os alunos, como 
por exemplo as cápsulas de sementes e as bandeirinhas inspiradas na cultura tibetana, com mensagens de paz. Essas ações colaboraram para uma unidade do projeto e a sua culminância na 46. ${ }^{a}$ Exposição Anual da Escolinha de Artes Infantis, com o tema "O que é paz para mim" (figura 8) (título pensado e escolhido pelos alunos por meio de votação), realizada na Galeria Municipal de Artes Victor Kursancew (figura 9).

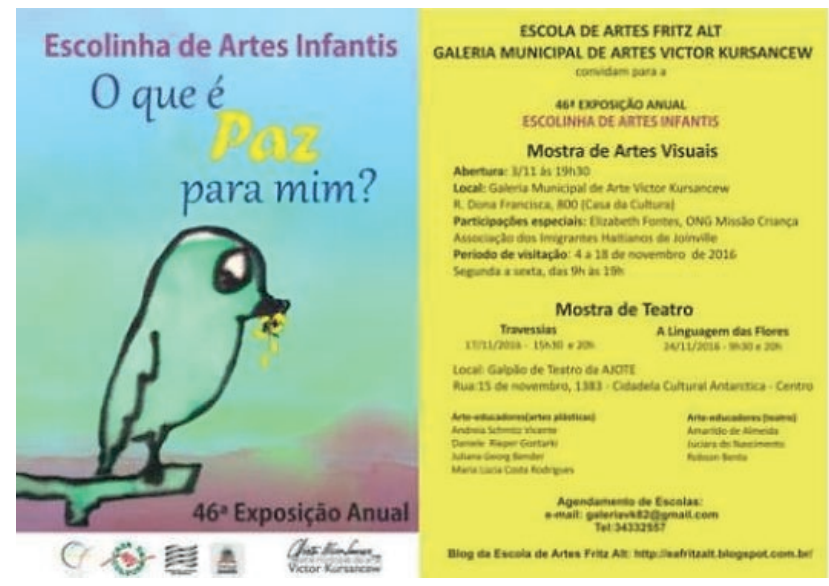

Figura 8: Convite da exposição "O que é paz para mim?" Fonte: Projeto gráfico de Maria Lúcia Costa Rodrigues ${ }^{8}$

8 A pintura em voal do pássaro que está no lado esquerdo do convite foi feito pela aluna Joana, de 8 anos. $O$ detalhe do pássaro deu origem à identidade visual da exposição. 


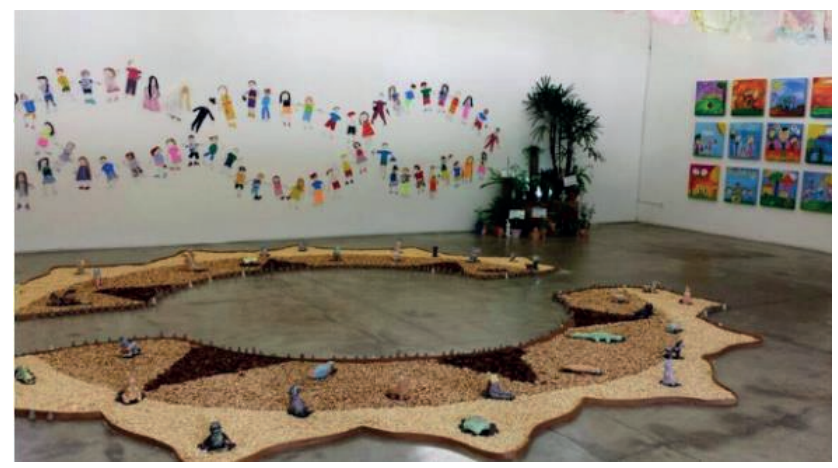

Figura 9: Foto da 46. ${ }^{a}$ Exposição da Escolinha na GMAVK ${ }^{9}$

Ao analisar o projeto "O que é paz para mim?", é possível identificar vestígios do modernismo no ensino da arte, como por exemplo nas ideias contidas em "Educação através da arte", de Herbert Read, um dos principais influenciadores do MEA, que "dá ênfase à esfera emocional do indivíduo, valorizando a sua originalidade e expressão da personalidade [...]. Nesta acepção, as artes visuais não eram entendidas como um fim, mas como um meio. Para Read [...], a arte deveria ser a base da educação" (LIBÂNIO, 2013, p. 14). Dessa forma, no projeto ora apresentado, a arte foi o caminho para o entendimento da Cultura de Paz.

Contudo não somente concepções modernistas foram identificadas. Ao trabalhar com o tema imigração, a Escolinha abordou outra face da pluralidade cultural, propiciando o conhecimento de culturas que não são muito divulgadas em nosso país, ao contrário da cultura norte-americana, presente constantemente nas músicas e na TV. Vários estudos dos últimos anos provam que uma das tendências da arte-educação contemporânea ou pós-moderna (IAVELBERG, 2015) é abordar a diversidade

9 A exposição recebeu uma média de 444 visitantes durante os 14 dias de visitação. Na parede esquerda: autorretratos feitos com bonecos articulados, produzidos pelas crianças da ONG Missão Criança e alunos de 7 e 8 anos da Escolinha. Na parede direita: pinturas com o tema "Pessoas que promovem a paz para mim", alunos de 6 e 7 anos. No chão: mandala usada como ambientação executada pela equipe do ateliê a partir de sensibilização e aprovação da expografia pelos alunos. A mandala simboliza o chacra do coração. Sobre ela estão os animais em cerâmica feitos por crianças de 6 anos. 
cultural (BARBOSA, 2011), caracterizando o ensino da arte como um ensino intercultural10. Barbosa (2011, p. 19) afirma que o interculturalismo

[...] significa a interação entre as diferentes culturas. Esse deveria ser o objetivo da Arte-Educação interessada no desenvolvimento cultural. [...] É necessário que a escola forneça um conhecimento sobre a cultura local, a cultura de vários grupos que caracterizam a nação e a cultura de outras nações.

Na arte-educação pós-moderna, a inter-relação entre ler, fazer e contextualizar arte é uma ação necessária para a compreensão da arte como conhecimento (BARBOSA, 2002), eixos presentes na Abordagem Triangular e que são trabalhados na Escolinha desde a década de 1990. lavelberg (2015, p. 77) afiança:

Hoje reconhecemos na arte de crianças e jovens a presença de visualidades do entorno próximo e distante. Deste último por meio da ampliação do acesso a imagens via internet e diferentes mídias; a arte infantil também sofre influência das tecnologias disponíveis na contemporaneidade.

Por isso, a Abordagem Triangular na Escolinha não se limita à leitura de imagens da história da arte, mas a muitos outros meios, como a literatura infantil com seus escritores e ilustradores, o audiovisual e a música. As ideias trazidas pelos alunos reforçam sua herança estética e artística com base no meio em que vive. Neste projeto, foi possível identificar algumas influências externas trazidas pelas crianças, como os temas meio ambiente e proteção aos animais; estes estiveram muito mais presentes nas vozes das crianças do que os temas imigrantes e culturas distintas, por exemplo. Isso ocorreu provavelmente porque as diferenças entre culturas ainda não estão interferindo diretamente na paisagem urbana e social da cidade e no cotidiano das crianças. Por fim, foi difícil de-

10 Barbosa (2011, p. 19) nos explica que, "enquanto os termos 'Multicultural' e 'Pluricultural' pressupõem a coexistência e mútuo entendimento de diferentes culturas na mesma sociedade, o termo 'Intercultural' significa a interação entre as diferentes culturas". 
finir qual a concepção metodológica mais precisa identificada no projeto, mas foi possível identificar raízes da arte-educação moderna e pós-moderna. Talvez esse "hibridismo" metodológico seja o resultado da longa trajetória da Escolinha no ensino da arte, aliado às transições temporais, políticas e artísticas sentidas na cidade, como foi explanado no início deste relato.

\section{REFLEXÕES E CONSIDERAÇÕES FINAIS}

A tradição dos projetos anuais realizados pela Escolinha é referência no meio educacional de Joinville. A exposição didática anual é o momento de compartilhar com a comunidade os processos de ensino e aprendizagem realizados durante cerca de sete meses de execução do projeto. Por meio da exposição “O que é paz para mim?" e das duas peças de teatro apresentadas pelos alunos de 10 e 11 anos da Escolinha, o processo e os resultados do projeto Cultura de Paz puderam ser divulgados.

A criança não é um sujeito passivo; é agente natural de mudanças em seu meio. Para mudar realidades sociais, faz-se necessário vivenciar uma constante Cultura de Paz. O projeto realizado em 2016 rendeu bons retornos: a Casa da Cultura implantou lixeiras para separação dos orgânicos, materiais recicláveis e rejeitos em sua unidade; os reflexos das ações da Escolinha durante o projeto renderam outros projetos dentro da Casa; houve um retorno muito positivo das famílias em relação ao comportamento das crianças fora da Escolinha.

Embora o foco do projeto se concentrasse em três eixos ("Meio ambiente", "Multiculturalismo" e "Combate às injustiças sociais"), sentimos que eles poderiam ser muito mais explorados, pois a Cultura de Paz é um tema muito envolvente e ao mesmo tempo conflituoso quando se pensa no contexto atual. As crianças se envolveram com suas criações e foram ativas na execução do projeto.

$\mathrm{O}$ acesso à diversidade cultural, trabalhando a empatia ao tentar se colocar no lugar do outro nos jogos de interação e nos relatos dos imigrantes, fez com que as crianças pudessem ter um novo entendimento e compreensão sobre as pessoas que saíram de seu país de origem em busca de melhores condições de vida. 
Em seus 49 anos de centro de formação em arte para a infância, milhares de crianças de Joinville e região passaram pela Escolinha, a qual enriqueceu a sensibilidade e a aprendizagem de gerações. A Escolinha de Artes de Joinville é um dos poucos espaços públicos de ensino não formal em arte para a infância no estado de Santa Catarina que atua ininterruptamente. É um espaço de salvaguarda da arte e da infância. Os projetos dos últimos anos têm demonstrado que a Escolinha valoriza a expressão e a criatividade da criança, mas também anda em consonância com a arte-educação pós-moderna. Ao mesmo tempo em que trabalha temas que sensibilizam o olhar da criança para si e para seu entorno, auxilia na busca de uma compreensão do que é estar, sentir e agir no mundo.

Se pensamos em paz, é porque o contrário existe, como a violência, a fome, as injustiças sociais e os males da alma. Por isso, a Cultura de Paz é um tema que deveria ser recorrente para todos em qualquer momento da vida, e não somente na educação. Quem sabe conhecendo, fomentando e atuando como agentes transformadores as crianças poderão tornar o mundo mais pacífico e humano para as próximas gerações. 


\section{REFERÊNCIAS}

BARBOSA, Ana Mae. A imagem no ensino da arte. São Paulo: Perspectiva, 2002.

BARBOSA, Ana Mae (org.). Ensino da arte: memória e história. São Paulo: Perspectiva, 2008.

BARBOSA, Ana Mae. Inquietações e mudanças no ensino da arte. São Paulo: Cortez, 2011.

CAPRARA, Andrea. Uma abordagem hermenêutica da relação saúde-doença. Cadernos de Saúde Pública, Rio de Janeiro, v. 4, n. 19, 2003. p. 923-931.

FREIRE, Ana Maria Araújo. Educação para a paz segundo Paulo Freire. In: Educação. Porto Alegre: v. 59, n. 2, 2006. p. 387-393

HERBST, Rubens. Exposição reúne 400 trabalhos de alunos da Casa da Cultura de Joinville. Disponível em: <https://ocp.news/ cultura/exposicao-reune-400-trabalhos-de-alunos-da-casa-dacultura-de-joinville>. Acesso em 07 abr. 2019.

IAVELBERG, Rosa. Arte-educação modernista e pós-modernista: fluxos. Tese (Livre-Docência - Metodologia do Ensino e Educação Comparada) - Faculdade de Educação da Universidade de São Paulo: São Paulo, 2015.

JOINVILLE LIXO ZERO. 2016. Disponível em https://www. facebook.com/pg/JoinvilleLixoZero/about/?ref=page_internal. Acesso em 10/5/2019.

LIBÂNIO, Anabela Marques Saraiva. Educação pela arte: uma experiência para dar sentido aos sentidos. Dissertação (Mestrado em Ciências da Educação) - Faculdade de Ciências Sociais e Humanas, Universidade Nova de Lisboa: Lisboa, 2013.

MOKROSS, Berenice Joanna. A importância da Escola de Artes "Fritz Alt" no contexto sócio-cultural joinvilense. Monografia 
(Especialização em A Prática Social da Arte: Educação e Sociedade) - Fundação Educacional de Joinville / Universidade de São Paulo: Joinville, 1992.

NEITSCH, Celiane. Projeto leva música clássica para crianças no Jardim Paraíso. Arte na Cuca, 29. set. 2018. Disponível em https://artenacuca.com.br/musica/projeto-leva-musica-classicapara-criancas-no-jardim-paraiso/. Acesso em 14/4/2019.

REVISTA DUO JOINVILLE. Albertina Tuma: um grande nome da cena cultural da cidade. Revista DUO Joinville. Joinville: ano 8, n. 50, ago. 2017. p. 80-83.

RIZZI, Maria Christina de Souza Lima. Reflexões sobre a Abordagem Triangular no Ensino da Arte. In: BARBOSA, Ana Mae (org.). Ensino da arte: memória e história. São Paulo: Perspectiva, 2008. p. 335-348.

STEFFEN, Heloísa. Escolinha de Artes Infantis de Joinville: 28 anos no cenário arte-educativo joinvillense. Monografia (Especialização em O Ensino da Arte: Fundamentos Estéticos e Metodológicos) - Universidade da Região de Joinville: Joinville, 1999.

VI COLETIVA de Artes Infantis. Jornal Joinville, 6 out. 1976. Acervo do Arquivo Histórico de Joinville. 